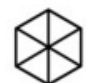 \\ LEUPHANA \\ UNIVERSITÄT LÜNEBURG
}

\section{Diversity as Polyphony}

Trittin, Hannah; Schoeneborn, Dennis

Published in:

Journal of Business Ethics

DOI:

10.1007/s10551-015-2825-8

Publication date:

2017

\section{Document Version}

Early version, also known as pre-print

Link to publication

Citation for pulished version (APA):

Trittin, H., \& Schoeneborn, D. (2017). Diversity as Polyphony: Reconceptualizing Diversity Management from a Communication-Centered Perspective. Journal of Business Ethics, 144(2), 305-322.

https://doi.org/10.1007/s10551-015-2825-8

\section{General rights}

Copyright and moral rights for the publications made accessible in the public portal are retained by the authors and/or other copyright owners and it is a condition of accessing publications that users recognise and abide by the legal requirements associated with these rights.

- Users may download and print one copy of any publication from the public portal for the purpose of private study or research.

- You may not further distribute the material or use it for any profit-making activity or commercial gain

- You may freely distribute the URL identifying the publication in the public portal ?

If you believe that this document breaches copyright please contact us providing details, and we will remove access to the work immediately and investigate your claim. 


\title{
Diversity as Polyphony: Reconceptualizing Diversity Management \\ From A Communication-Centered Perspective
}

\author{
Hannah Trittin \\ University of Zurich \\ Department of Business Administration \\ Universitaetstr. 84 \\ 8006 Zurich \\ Switzerland \\ hannah.trittin@business.uzh.ch
}

\author{
Dennis Schoeneborn \\ Copenhagen Business School \\ Dept. of Intercultural Communication and Management \\ Porcelaenshaven 18A \\ 2000 Frederiksberg \\ Denmark \\ dsc.ikl@cbs.dk
}

This is a pre-print version of a journal article. The published paper can be found here:

Trittin, H., \& Schoeneborn, D. (in press). Diversity as Polyphony: Reconceptualizing Diversity Management from a Communication-Centered Perspective. Journal of Business Ethics.

\section{Acknowledgements}

We thank section editor Nicola Pless and the three anonymous reviewers for their guidance and advice. We also thank Nicolas Bencherki, Bill McKinley, Heike Mensi-Klarbach, Jawwad Raja, Robyn Remke, Jens Rennstam, Andreas G. Scherer, Steen Vallentin, Florence Villesèche, Christian Vögtlin, and Glen Whelan for their valuable comments regarding earlier drafts of this paper. 


\title{
Diversity as Polyphony: Reconceptualizing Diversity Management From a Communication-Centered Perspective
}

\author{
Hannah Trittin, University of Zurich, hannah.trittin@business.uzh.ch \\ Dennis Schoeneborn, Copenhagen Business School, dsc.ikl@cbs.dk
}

Paper accepted for publication in the Journal of Business Ethics

\begin{abstract}
In this paper, we propose reconceptualizing diversity management from a communicationcentered perspective. Our proposal is based on the observation that the literature on diversity management, both in the instrumental and critical traditions, is primarily concerned with fostering the diversity of organizational members in terms of individual-bound criteria (e.g., gender, age, or ethnicity). By drawing on Bakhtin's notion of polyphony as well as the ‘communicative constitution of organizations' (CCO) perspective, we suggest reconsidering diversity as the plurality of 'voices', that is, the range of individual opinions and societal discourses that become expressed and can find resonance in organizational settings. We contribute to the literature on diversity management by moving away from a focus on individual-bound and inalterable criteria of diversity and towards a reconceptualization of diversity management as dynamic processes of voice articulation and mediation.
\end{abstract}

\section{Keywords}

Bakhtin; 'communicative constitution of organizations' (CCO); diversity management; organizational communication; polyphony 


\section{Introduction}

In 2009, the Dutch telecommunications company KPN adopted a policy that prioritized women as candidates for top management positions (Dutchnews.nl, 2014). Flouting this policy was penalized: for example, KPN managers who did not hire women suffered a reduction in their bonuses. Recently, however, KPN publicly abolished this policy. The firm reported that the women hired were ultimately very similar to their male counterparts in terms of their skill sets, capacities, career paths, and educational backgrounds. Because of the high degree of similarity, according to KPN's management, the measure did not fulfill its purpose, which was to increase the diversity of the workforce and allow different viewpoints and work styles to vitalize the corporation (Dutchnews.nl, 2014).

As the KPN case demonstrates, measurements to increase workforce diversity in terms of predefined, individual-bound, and largely inalterable characteristics of differences between human beings (see also Tatli and Özbilgin, 2012) cannot guarantee that novel and alternative viewpoints get expressed and find resonance in organizational settings. Existing literatures on diversity management offer only limited guidance in this matter. On the one hand, diversity management research in the 'instrumental' tradition (e.g., Cox and Blake, 1991; Robinson and Dechant, 1997; Scott et al., 2011) is concerned with how organizations can manage the diversity of organizational members along sociodemographic criteria (e.g., gender, age, or ethnicity) in order to gain competitive advantage and enhance team performance (an approach that the KPN example renders questionable). On the other hand, diversity management research in the 'critical' tradition draws on normative arguments to stress the importance of workforce diversity, for instance, based on ideals of social justice and social representation (e.g., Van Dijk et al., 2012). At the same time, works in the critical tradition also highlight the challenges, tensions, and contradictions of realizing those ideals in organizational practice (e.g., Bissett, 2004; Kalonaityte, 2009; Kirton and Greene, 2009; Riach, 2009). 
Despite these different orientations, both traditions of diversity management research are united by their focus on the organization's workforce, i.e. how to diversify the population of individual human members. However, this focus precludes from acknowledging that also non-members can significantly contribute to an organization's diversity. Thus, in this paper, we develop the argument that diversity management research and practice can benefit from being complemented by a communication-centered perspective. More specifically, by drawing on the work of Bakhtin (1984; Carter and Clegg, 2003; Hazen, 1993; Kornberger et al., 2006) and the emerging 'communicative constitution of organizations' (CCO) perspective (Ashcraft et al., 2009; Brummans et al., 2014; Cooren et al., 2011), we propose the reconceptualization of diversity as the plurality of 'voices', that is, the range of individual opinions and societal discourses that become expressed and can find resonance in organizational settings. Importantly, in line with Bakthin (1984), we understand voices as existing partly independent from specific individuals; in other words, one and the same voice can be expressed by different individuals and through one and the same individual multiple voices can become expressed (see also Belova et al., 2008; Belova, 2010; Pietikäinen and Dufva, 2006). Our conceptual inquiry is guided by the following question: What are the implications for diversity management when the goal switches from a diversification of the workforce along individual-bound criteria (such as gender, age, or ethnicity) towards a diversification of voices that get expressed and/or find resonance in organizational settings?

With regards to the instrumental tradition, we argue that the switch of focus to the diversity of voices allows diversity management to tap into the potential for innovation, creativity, and change that lies in the communicative appreciation of otherness (see also Bassett-Jones, 2005). With regards to the critical tradition, we posit that a communication-centered approach can pave the way to a different kind of social representation: not in the sense of social representation of certain groups of individuals (in terms of individual-bound, 
sociodemographic criteria) but in the sense of a representation of societal voices and discourses in organizational settings (what we suggest to term 'discursive diversity'1). Switching to voices as the main focus of diversity management thus can help account for the fundamental embeddedness of organizations in a 'networked society’ (Schultz et al., 2013).

Our contributions to the existing literature on diversity management and communication are threefold: first, we contribute to diversity management research by extending the idea of diversity towards communicative plurality. Importantly, by switching the focus to the diversification of (organizational and contextual) voices, our approach allows for reconciling the idea that diversity is necessary for innovation and change (one key focus in the instrumental tradition) with normative considerations on inclusion and social representation (one key focus in the critical-tradition). Second, our reconceptualization of diversity management draws attention to importance of contextual voices as sources of diversity (i.e. voices that become articulated in society-at-large). In this regard, our paper helps consider diversity management as an important part of corporate social responsibility (CSR) which similarly demands from organizations to consider broader societal discourses and stakeholder relations (e.g., Maak and Pless, 2006; Matten and Moon, 2004; Scherer and Palazzo, 2007). Finally, we also contribute to CCO as a theoretical endeavor (Ashcraft et al., 2009). We demonstrate fruitful cross-connections of the CCO perspective with other works that highlight the multi-voiced character of organizations (Belova et al., 2008; Hazen, 1993) and the organizational need for practicing polyphonic dialogues in day-to-day organizing (Pless, 1998, 1999). By relying on Bakhtin-inspired dialogism (Bakhtin, 1984; Shotter, 2008), we furthermore help further unpack the ethical implications of the CCO perspective (see also Scherer and Rasche, forthcoming).

\footnotetext{
${ }^{1}$ The term 'discursive diversity' is not entirely new but has been used in other contexts before. For instance, Flores and McPhail (1997) draw on the same term in the area of media studies for critically discussing the role of mass media in contributing to the social construction of (individual human) differences.
} 


\section{Literature Review on Diversity Management and Communication}

The field of diversity management comprises a rich body of research that is part of the even larger, cross-disciplinary field of diversity research. Diversity management research includes studies from the areas of human resource management (e.g., Alcázar et al., 2013; Bell et al., 2011; Scott et al., 2011), innovation management (e.g., Bassett-Jones, 2005), or organization and management studies more generally (e.g., Cox and Blake, 1991; Francoeur et al., 2007; Siciliano, 1996). Comprehensive overviews on the subject can be found in various recent special issues of academic journals (e.g., Metcalfe and Woodhams, 2012; Nishii and Özbilgin, 2007; Zanoni et al., 2010). In the following literature review, we present and analyze the two primary streams of research on diversity management: the instrumental and the critical tradition. An exhaustive review of the vast field of diversity management is beyond the scope and the goal of this paper. Instead, in line with our theoretical focus, our literature review is guided by the question how existing works on diversity management understand communication and how these studies can contribute to a communication-centered understanding of diversity management.

\section{Instrumental Perspectives on Diversity Management}

A significant stream of scholarship on diversity management examines how organizations can use diversity instrumentally in order to gain competitive advantage and enhance organizational or team performance (e.g., Cox and Blake, 1991; Labucay, 2015; Robinson and Dechant, 1997; Scott et al., 2011). Researchers following the 'instrumental' tradition (Janssens and Zanoni, 2005) tend to conceptualize diversity as the difference between individuals. Although this generic conceptualization of diversity can apply in principle to "any attribute that may evoke the perception that the other person is different from the self" (Guillaume et al., 2013, p. 124; see also Van Knippenberg and Schippers, 2007; Williams and 
O’Reilly, 1998), theoretical models of diversity management in this tradition tend to rely primarily on sociodemographic attributes such as gender, age, or ethnicity (e.g., Cox and Blake, 1991; Cox, 1991; Gilbert and Ivancevich, 2000; Ivancevich and Gilbert, 2000).

The aim of scholars following the instrumental tradition is "to get diversity at work to work" (Guillaume et al., 2013, p. 124). Accordingly, various empirical studies investigate how organizations can establish formal programs that enable them to manage workforce diversity most effectively and generate competitive advantage (e.g., Cox and Blake, 1991; Milliken and Martins, 1996; Wright et al., 1995). These ‘toolkits’ typically include specific human resource management (HRM) practices such as recruitment, training, leadership, or mentoring programs (e.g., Alcázar et al., 2013; Gilbert et al., 1999; Ivancevich and Gilbert, 2000; Kulik, 2014; Roberson et al., 2001). On the whole, these studies regard organizations as capable of strategically implementing structures, processes, and policies in order to leverage the ‘business case’ of diversity (Labucay, 2015; Robinson and Dechant, 1997).

Most works in the instrumental tradition propose that communication either supports or interferes with the positive influence of diversity management on organizational performance (e.g., Ayoko, 2007). More precisely, communication is viewed here primarily as a factor that moderates the influence of diversity on performance (e.g., Ashkanasy et al., 2002; Ayoko, 2007; Findler et al., 2007; Grimes and Richard, 2003). For instance, some scholars suggest that organizations should encourage ‘cosmopolitan communication' (Grimes and Richard, 2003) and thus demonstrate their appreciation of the differences between individuals in order to sustain competitive advantage (e.g., Grimes and Richard, 2003). Other scholars recommend that organizations should create environments in which 'diverse' employees (e.g., in terms of ethnic background) feel safe and are encouraged to speak their mind, because this will induce them to contribute subsequently to the organization's success by doing more than their role prescriptions require (Singh et al., 2013). Further empirical studies imply that a favorable 
organizational culture, or 'climate' (Cox Edmondson et al., 2009), in which the value of diversity is addressed, increases employee satisfaction and commitment and leads to desirable outcomes for the organization (e.g., Cox Edmondson et al., 2009; Groggins and Ryan, 2013; Nelson and Wolf, 2012). Thus, creating favorable communicative situations is viewed here as key to unleash the productive effects of diversity in organizational settings (e.g., Grimes and Richard, 2003; Naff and Kellough, 2003).

Notwithstanding the merits of the instrumental perspective on diversity management (especially its guidance in the application of these practices for business purposes), we should note that works in this tradition tend to portray communication as a unidirectional, controllable, and linear process through which the organization transmits information to its constituents (for a critical review of this notion of communication, see Axley, 1984). For instance, Barker and Gower (2010) suggest that organizations should utilize practices of storytelling as a communication tool to strategically persuade heterogeneous audiences across the organization. More broadly, research on instrumental diversity management seems to be grounded in the underlying assumption that the organization is in control of its communication, including what information is transmitted and how audiences will receive it. At the same time, most of these studies imply a 'container' metaphor of organization in the sense that they conceive of organizations as distinct entities in which communication processes occur. These assumptions, however, tend to neglect the fundamental, constitutive, and formative role of communication for organizations (Cooren et al., 2011).

Recent, practitioner-oriented works in the instrumental tradition have drawn attention to new and alterable dimensions of diversity (e.g., Helgesen, 2014). For instance, as Freeman (2014) reports, some corporations have taken measurements to diversify their workforce with respect to dynamic and alterable criteria such as work styles or value orientations. This development in organizational practice corresponds with a more general trend in the academic literature to 
draw on more fine-grained conceptualizations of diversity and to investigate the effects of diversified value orientations (e.g., Eastman and Santoro, 2003), work styles (e.g., Shelton et al., 2002), or educational backgrounds (e.g., Kearney et al., 2009) on organizational performance. We consider these works as useful first steps towards a reconceptualization of diversity management based on alterable and dynamic criteria of diversity.

\section{Critical Perspectives on Diversity Management}

In contrast to the instrumental tradition, other scholars have proposed a critical approach that takes into account the inherently contested and political character of the concept of diversity management (e.g., Metcalfe and Woodhams, 2012; Syed and Özbilgin, 2009; Tatli, 2011; Tatli and Özbilgin, 2012; Zanoni et al., 2010). Within the critical tradition, we can broadly distinguish between, on the one hand, 'radical-critical' works which tend to reject the manageability of diversity in organizational settings (e.g., Bissett, 2004; Kalonaityte, 2009; Swan, 2009) and, on the other hand, 'constructive-critical' works which follow a more modest approach. These latter works aim to reconcile the critical with the instrumental perspective to some degree by proposing diversity management approaches that are both economically successful and socially just (e.g., Janssens and Zanoni, 2014; Jonsen et al., 2013; Nishii and Özbilgin, 2007).

In the 'radical-critical' stream of the literature, some scholars fundamentally contest the business rationale of diversity management and the underlying assumption that human diversity would be manageable (e.g., Zanoni et al., 2010). In this stream of the literature, organizations are understood as political systems that tend to reproduce social injustice (Adler

et al., 2007) by systematically disadvantaging, under-representing, or silencing organizational members such as women, ethnic minorities, or homosexuals (e.g., Bell et al., 2011; Kamenou and Fearfull, 2006; Litvin, 1997). In the same line of thinking, scholars emphasize that the 
term 'diversity management' rhetorically obscures injustice in organizational settings, without addressing contextual conditions of power, privilege, inequality, and disadvantage (e.g., Bissett, 2004; Kirby and Harter, 2003; Litvin, 1997). In particular, these studies assert that judging people by sociodemographic and individual-based criteria of diversity (such as gender, age, ethnicity, or sexuality) leads to the exclusion and suppression of certain groups of organizational members (Kamenou and Fearfull, 2006). Moreover, seen from this perspective, diversity management approaches based on sociodemographic criteria of diversity can become sources of domination and alienation, as they reinforce (rather than help overcome) the separation and distinction between individuals (e.g., Bissett, 2004; Kalonaityte, 2009; Swan, 2009).

Other scholars have recently departed from such radical-critical views. Scholars following a 'constructive-critical' approach argue normatively that corporations should practice diversity management programs that foster the inclusion and social representation of individuals within the organization in order to fight inequality (Gotsis and Koretzi, 2013). For this purpose, constructive-critical scholars explore how diversity management practices are shaped by the 'language in use' (e.g., Janssens and Zanoni, 2005, 2014; Tomlinson and Schwabenland, 2009; Van Laer and Janssens, 2011; Zanoni, 2011). Thus, constructive-critical scholars tend either to be concerned with the role of language in perpetuating or challenging organizational power relations (Zanoni and Janssens, 2004) or highlight the relevant experiences of organizational members-for example, the discrimination that some employees face and the suppression they may suffer as a result of particular practices of diversity management (e.g., Kamenou and Fearfull, 2006; Schwabenland and Tomlinson, 2015).

In the same constructive-critical tradition, scholars have argued that diversity management research and practice should depart from predefined and static individual-bound categories (e.g., Tatli and Özbilgin, 2012). For instance, Özbilgin and his colleagues (e.g., Jonsen et al., 
2013; Nishii and Özbilgin, 2007; Syed and Özbilgin, 2009; Tatli and Özbilgin, 2012) suggested to apply an 'intersectional' approach to diversity management. This approach is based on a fluid understanding of diversity, according to which categories such as gender intersect with other categories, such as race, but are continually (re)negotiated in action (Styhre and Eriksson-Zetterquist, 2008). Consequently, these studies view individual discrimination as the result of intersecting systems of oppression and point out the dynamics as well as the pitfalls of static, individual-based conceptualizations of diversity (Styhre and Eriksson-Zetterquist, 2008; Syed and Özbilgin, 2009; Zanoni et al., 2010). Going back to our initial example of the Dutch company KPN, an intersectional approach can explain the change in policy as follows: because the education and training of the women that the firm hired on account of their gender were too similar to those of their male counterparts, they did not bring the qualities that were expected of them. In the eyes of KPN, they did not perform their 'femaleness' sufficiently. Consequently, studies that are based on intersectionality explicitly call for the creation of dynamic and relational approaches to managing diversity that are sensitive to the interplay of inequality dynamics in organizational settings and society at large (Tatli and Özbilgin, 2012).

Overall, within the critical stream of research, scholars differ in their assessments of the role of communication for diversity management. On the one hand, studies in the radical-critical tradition tend to dismiss corporate communication on diversity management altogether on the grounds that it perpetuates rather than eliminates discrimination (e.g., Bissett, 2004; Litvin, 1997; Singh and Point, 2006). Many critical scholars view communication in this context as mere 'window dressing' that allows organizations to pretend to appreciate a diverse workforce without, however, implementing practices that create genuine equal opportunities (e.g., Singh and Point, 2006). Within the constructive-critical tradition, on the other hand, some scholars put forth a performative view of diversity (e.g., Janssens and Zanoni, 2005; 
Tienari and Nentwich, 2012), emphasizing the importance of communication in the social construction of diversity meanings. In this view, communication not only represents but also produces social reality (see also Austin, 1962; Searle, 1969). Yet, most of these studies primarily criticize the negative social consequences of various constructs of diversity for individuals in organizational contexts but do not relate the idea that language use has a formative role to the ontology of the organization, i.e., its communicative constitution (Ashcraft et al., 2009).

Thus, in this paper, we build upon and go beyond the constructive-critical stream of diversity management research by considering the constitutive and formative force of communication not only with regard to the concept of diversity, but also with regard to organizations as communicative entities (Cooren et al., 2011). Specifically, we argue that organizations and their business practices are subject to processes of communicative construction that may involve contextual voices, i.e. individual voices as well as larger societal discourses 'outside' of the organization's (permeable) boundary. For instance, Prasad et al. (2011) have described how practices of organizational diversity are shaped by industry-wide 'discourses of fashion'.

In the following, we propose a communication-centered approach to diversity management that takes into account the influence of these contextual voices on organizing processes and thus, as mentioned previously, leads to a different understanding of social representation. In other words, our reconceptualization implies moving the focus away from individual human beings (and their characteristics) and instead focuses on the plurality of organizational and contextual voices as the primary unit of analysis, i.e. individual opinions and societal discourses that become expressed and find resonance in organizational settings. 


\section{The Theoretical Foundations of a Constitutive-Polyphonic Perspective}

A growing body of literature suggests that the relation of communication to organization is constitutive in character; in other words, that communication constitutes organizations (CCO) (for recent overviews, see Ashcraft et al., 2009; Brummans et al., 2014; Cooren et al., 2011). In the CCO perspective, communication is seen as "axial-not peripheral to organizational existence and organizing phenomena” (Ashcraft et al., 2009, p. 22). Organizations are thus imagined here as precarious social entities (Nicotera, 2013) that necessitate to become continuously (re)incarnated in and through the occurrence of interconnected communicative practices (Blaschke et al., 2012; Nicotera, 2013).

In the following, we treat the CCO perspective as an integrated theoretical endeavor, while keeping in mind some key epistemological and methodological differences between the various schools of CCO thinking (see also Brummans et al., 2014; Kuhn, 2012; Schoeneborn et al., 2014). Within the CCO perspective, our argumentation primarily follows the work of the 'Montreal School' (e.g., Bencherki and Cooren, 2011; Cooren, 2004, 2012; Taylor and Cooren, 1997). This is because this line of CCO thinking tends to contrasts most strongly with the transmission view of communication (Axley, 1984) and is thus particularly helpful for our inquiry.

In line with Cooren and Sandler (2014), we argue that the CCO perspective and particularly the idea that organizations come into being through multiple interconnected communicative practices (e.g., Blaschke et al., 2012; Taylor and Van Every, 2000) exhibit striking similarities to the idea of the 'polyphonic organization' (Hazen, 1993). Both streams of the literature emphasize that it is important to attend to the plurality of voices in organizational contexts (e.g., Belova, 2010; Christensen and Cornelissen, 2011; Cooren and Sandler, 2014; Hazen, 1993; Shotter, 2008). However, while the majority of works that follow the CCO perspective 
tend to be descriptive in nature (for an overview on rare exceptions, see Ashcraft et al., 2009), scholars who work with the notion of polyphony tend to employ this concept to make normative claims about organizations. In this latter view, organizations should be open to the equal expression of diverse voices. The expression of a plurality of voices is understood here as an important prerequisite for innovation and change as well as ethically responsible organizing (e.g., Carter and Clegg, 2003; Jabri et al., 2008; Kornberger et al., 2006).

Building on both streams of the literature, in what follows, we use the label 'constitutivepolyphonic' to emphasize that our viewpoint goes beyond the CCO perspective as it incorporates the normative claim (from research on polyphony) that it is worthwhile for organizations (and society more generally) to embrace dissent and the plurality of voices in a dialogic way. In the following, we will delineate this combined constitutive-polyphonic perspective on the basis of three main tenets.

\section{(1) Organizations as Emergent and Polyphonic Phenomena}

Proponents of the CCO perspective highlight the formative role of communication for social realities and material structures. This ‘constitutive’ notion of communication (Cooren, 2012; Craig, 1999) is grounded in 'speech act theory’ (Austin, 1962; Searle, 1969), which argues that utterances tend to be 'performative' in character; in other words, utterances do not only represent, but actively contribute to the creation of social reality. In stark contrast to viewing communication as a 'conduit', a metaphor that implies a simple and friction-free transfer of information or ready-made meanings between senders and receivers (Axley, 1984), CCO scholars depict communication as an inherently complex, dynamic, and precarious accomplishment (e.g., Cooren et al., 2011).

According to the CCO view, organizational phenomena arise from a multitude of recurrent and interconnected communicative practices that are enacted on its behalf (Bencherki and 
Cooren, 2011; Taylor and Cooren, 1997), including communicative practices such as diversity management. Accordingly, organizations are seen here as emergent formations that tend to be created by multiple and potentially dissonant voices (Christensen and Cornelissen, 2011). In this regard, the CCO perspective's concept of diversity exhibits striking similarities to Bakhtin's notion of 'polyphony' that has been used by organization scholars to highlight the multi-voiced character of organizations (Bakhtin, 1984; Belova et al., 2008; Hazen, 1993). Proponents of the polyphonic viewpoint suggest that organizational practices should be understood as “multi-centered, non-linear and intersubjective activities” (Belova et al., 2008, p. 494). From this perspective, the 'polyphonic organization' (Hazen, 1993; see also Belova, 2010; Belova et al., 2008; Kornberger et al., 2006; Shotter, 2008) does not have one voice, as the idea of 'integrated communication’ might imply (for a critical discussion, see Wehmeier and Winkler, 2013), but results from the expression of multiple voices. When the organization speaks (or acts), many voices (i.e., individual voices and societal discourses) may speak through it.

\section{(2) The Involvement of Contextual Voices in the Communicative Constitution of}

\section{Organizations}

Works that adopt the CCO viewpoint question the clear-cut distinction between the 'inside' and 'outside' of organizations (e.g., Christensen and Cornelissen, 2011). According to these works, the organizational boundary is relatively fluid, permeable, and ambiguous and thus needs to be maintained recurrently through speech acts that demarcate what the organization is and what it is not (Bencherki and Cooren, 2011; Dobusch and Schoeneborn, 2015). Importantly, the idea of permeable boundaries suggests that contextual voices can partake in the communicative co-constitution of organizations (Kuhn, 2008). In this view, organizations are incarnated through communicative practices that allow actors to claim the authority to speak in the organization's name (Taylor and Cooren, 1997). Importantly, communicative 
practices can be invoked independently of whether or not such claims are uttered by members or non-members of the organization, as long as these speech acts contribute to the attribution of collective actorhood to organizational phenomena (Bencherki and Cooren, 2011; Dobusch and Schoeneborn, 2015). Thus, what is 'inside' and 'outside' the organization is contextually bound and tends to become continuously negotiated through communication.

In this perspective, the boundary of an organization is demarcated through the inclusion or exclusion of specific voices, rather than individual members (see also McPhee and Zaug, 2000). Thus, the boundaries of an organization are drawn communicatively, through the authorization of specific voices that are allowed to speak on the organization's behalf (Taylor and Van Every, 2014). It follows that organizations need to maintain their identity continuously through communicative interactions that may involve organizational members and/or non-members (Dobusch and Schoeneborn, 2015). In other words, from this view, we can understand diversity management as a form of organizational boundary management that needs to be receptive to the diversity and complexity of environmental and societal voices, while being able to ensure the organization's status as a (more or less) distinct entity, at the same time.

\section{(3) The Polyphonic Dialogue as Guiding Principle of Organizing}

We suggest that CCO theorizing can be usefully combined with Bakhtin's notion of 'polyphony' (Bakhtin, 1984; see also Cooren and Sandler, 2014). Bakhtin's idea of polyphony, which he developed in the context of literature studies, has found increasing reception in organization studies (e.g., Belova, 2010; Belova et al., 2008; Hazen, 1993; Kornberger et al., 2006). In Bakthin's view (1984) communication is inherently relational and dialogic: because individuals think and act always in relation to each other, their utterances do not only represent their individual perspective but also include the overall context of the 
interaction, that is, the larger societal discourses in which they are embedded (Bakhtin, 1984; Gardiner, 2004).

In his discussion of polyphony, Bakhtin highlighted the importance of dialogue (e.g., Bakhtin, 1984; Shotter, 2008). To understand this focus better, it is worthwhile recalling that the idea of polyphony originates in music. In a polyphonic composition, voices are respected for their own timbre and are not unified in a single voice (Christensen et al., 2008); instead, they are temporarily connected in a dialogic way. Bakhtin employed the notion in his discussion of Dostoyevsky's novels. In a nutshell, he argued that in polyphonic settings, when several voices are linked in the unifying moment of dialogue, authority is not retained by a single voice such as the voice of the author of a novel (Bakhtin, 1984). Although true consent or understanding can never be reached (a point where Bakhtin departs from Habermasian discourse ethics; see Habermas, 1991), the dialogic process is a desirable end in itself because it connects various voices in a particular context at any given moment (Gardiner, 2004).

Organizational scholars who are drawing on the notion of polyphony tend to argue that organizations should be studied as discursive spaces that should allow different voices to be expressed (e.g., Hazen, 1993; Kornberger et al., 2006; Pless, 1998). Viewing organizations as polyphonic phenomena implies that multiple voices are dynamically combined, rather than merged, in dialogue (Hazen, 1993) and may challenge authoritative tendencies (Kornberger et al., 2006). Works that have been influenced by Bakhtin's initial ideas emphasize that centripetal forces (i.e., hegemonic tendencies towards harmonization) and centrifugal forces (i.e., resisting voices that tend toward heterogeneity) can coexist in organizational settings (e.g., Brown, 2006; Geiger and Antonacopoulou, 2009). However, organizations are presumed to strive towards communicative homogeneity as “dominant discourses seek to shut down diversity by limiting the possibilities of sensemaking to a privileged and limited range of discursive strategies" (Carter and Clegg, 2003, p. 296). Some scholars argue that 
facilitating polyphony holds the potential for organizational change (e.g., Carter and Clegg, 2003; Christensen et al., 2015; Jabri et al., 2008; Kornberger et al., 2006). Accordingly, these authors suggest following the ideal of the polyphonic dialogue, i.e. a moment in which various dissonant voices are linked dialogically but without merging, as a guiding principle of organizing (e.g., Kornberger et al., 2006; for a critical view see Letiche, 2010).

However, Bakhtin (1984) does not provide clear guidance on how to practice such polyphonic dialogue in organizational settings. In turn, we find the works by Pless $(1998,1999)$ useful for filling this gap. Pless (1998) argues that corporate management initiatives aiming to solve ecological crises oftentimes fail because firms do not engage actively with dissensual and marginal voices of internal and external stakeholders in a polyphonic way. In order to overcome this dilemma, she stresses five guiding principles for conducting polyphonic dialogues between corporations and their internal and external stakeholders (Pless, 1998, pp. 315-325; for similar remarks, see Cunliffe and Eriksen, 2011): First, one important requisite for a polyphonic dialogue is the mutual recognition of all participants of the dialogue. Second, the establishment of long-lasting relations with each other enables all sides to develop reciprocal trust. Only then, as Pless $(1998,1999)$ accentuates, will people feel free to speak their minds. Third, corporations need to give people room to develop and express their voices. Following the principle of mutual enabling, corporations should demonstrate that they care for these voices and thus actively encourage people to bring their (marginalized) voices to the fore. Fourth, corporate managers should also foster mutual understanding of different viewpoints, which can be achieved by addressing directly underlying assumptions or bias. Finally, her approach emphasizes the importance of 'multiloguing' (Pless, 1998, p. 324), i.e. the negotiation between multiple logics of the participants of a dialogue - as a precondition of forming a common basis of understanding. For Pless (1998), these five principles and the idea 
of all voices to be "different but equal” (p. 321) are the foundation for common, mediated negotiation between all participating voices in a polyphonic dialogue.

Pless (1999) was also among the first scholars to identify fruitful links between the notions of diversity management and polyphony (for another rare exception, in Danish language, see the work by Rennison, 2009). Pless stresses the necessity of establishing communicative processes within corporations that enable marginalized and 'different' voices of culturally different employees to speak up (Pless, 1999). Furthermore, she emphasizes that embracing alternative voices enables corporations to tap into the innovative and creative potential of bringing together different viewpoints, experiences and knowledge. Importantly, her argumentation is based in the assumption that "organizations are constructs that through the communicative discourses of their employees and with their social and cultural environment take on a particular 'Gestalt' (shape)” (Pless, 1999, p. 164; own translation). Thus, Pless puts forth a relational ontology of organizations that exhibits similarities to what is known as the CCO perspective today (Cooren et al., 2011).

Consequently, we understand the work by Pless $(1998,1999)$ as an important precursor for our polyphonic-constitutive reconceptualization of diversity management. We argue that recent works from the CCO perspective (Cooren et al., 2011) are helpful to expanding Pless’s argumentation to the full consequentiality of a communication-centered ontology of organizations (Nicotera, 2013). If voices become the main matter of concern and if voices are not bound to specific individuals (see Bakhtin, 1984), it becomes important for diversity management not only to foster the expressivity of voices by organizational members but also to become attentive to the voices that get expressed through larger societal discourses, i.e. in supra-individual form. In the following, we will elaborate on the practical and ethical implications of reconceptualizing diversity management as a polyphonic endeavor. 


\section{Toward a Constitutive-Polyphonic Reconceptualization of Diversity Management and Communication}

Our review of the diversity management literature has aimed to show that, despite a broad range of understandings of the diversity concept, research in both the instrumental and the critical traditions tends to be primarily concerned with fostering the 'within-unit' diversity (Harrison and Klein, 2007) between individual organizational members (e.g., Cox and Blake, 1991; Harrison and Klein, 2007; Kamenou and Fearfull, 2006; Riach, 2009; Scott et al., 2011; van Laer and Janssens, 2011). Our own constitutive-polyphonic view departs from prior research on diversity management by treating the diversity of communicative practices (rather than the diversity of individuals) as the primary unit of analysis (see also Ashcraft et al., 2009). We argue that for organizations to be able to act (responsibly) in a networked society (Schultz et al., 2013), they must consider the diversity of organizational and contextual voices and encourage dissonant voices to be heard and included.

Table 1 summarizes and compares the main differences between the streams of diversity management scholarship that we discussed in the previous section and our constitutivepolyphonic view.

Insert Table 1 about here

In the preceding section we discussed how the 'ends' of diversity management can be defined on the basis of polyphony. In this section, we elaborate on the 'means' that can be used to achieve these ends and discuss the implications of a constitutive-polyphonic understanding of diversity management in three main application areas. 
In a nutshell, we argue that the likelihood of voices becoming expressed in an organization can be increased in three exemplary ways: (1) by using the human resources management (HRM) practices of recruitment and promotion to incorporate the goal of increased polyphony of organizational voices, (2) by fostering structural resonance in order to accommodate the polyphony of contextual voices, and (3) by nurturing the interplay between organizational and contextual voices through responsible leadership practices, an inclusive organizational culture, and educational measurements. We discuss each of these application areas in further detail below.

\section{(1) Facilitating the Polyphony of Organizational Voices}

Existing works from the instrumental perspective on diversity management provide insights into how organizations can implement HRM practices aimed at managing the diversity of organizational members (e.g., Alcázar et al., 2013; Kulik, 2014). For example, diversityoriented recruitment practices are seen here as a strategic way of enhancing variety of the applicant pool and an organization's workforce (e.g., Scott et al., 2011). Promotion practices that favor diversity are presumed to have similar effects (Cox and Blake, 1991; James, 2000). However, critical studies point out that diversity management measures that rely on predefined categories of difference may have ambiguous and perhaps even negative consequences for particular groups of organizational members (Tatli and Özbilgin, 2012) and question whether such procedures can actually achieve their goal of increasing organizational diversity.

As examples from organizational practice such as the KPN case illustrate, it is problematic to assume that diversity in terms of attributes such as gender or race automatically results in the diversification of viewpoints, ideas, or opinions (see also Zanoni et al., 2010). In our view, implementing recruitment or promotion practices that prioritize particular groups of 
organizational members, such as stipulating quota on the basis of gender, race, and similar sociodemographic attributes may help increase social representation within the organization but do not necessarily ensure polyphony in the sense of 'discursive diversity' (i.e. the representation of societal discourses and voices). In response to this issue, our constitutivepolyphonic approach suggests that it is important to consider the conditions that favor the polyphony of organizational voices and that allow for the expression of dissent and otherness as a key way of increasing diversity. Our approach implies that communicative procedures, structures, and cultures need to be designed in a way so that they increase the likelihood for the expression of organizational polyphony (or at least the establishment of a counter-weight to organizational tendencies towards a homogenization of voices; see Carter and Clegg, 2003, p. 296).

In the context of HRM practices, in order to increase the variety of voices in organizational contexts, polyphony would need to become a guiding principle in the recruitment, retention, and promotion of members. For instance, our proposed approach implies turning the focus away from individual (e.g., sociodemographic) attributes that the applicant might bring to the organization. Instead, from our constitutive-polyphonic viewpoint, the key question is which candidates for recruitment or promotion are most likely to make a team more diverse in terms of views, attitudes, and values (see also Pless and Maak, 2004, pp. 133-134).

As we discussed earlier, Bakhtin (1984) envisions communication as a relational and contextbound dialogic process. Applying this principle to organizations, we suggest that procedures of recruitment and promotion should furthermore involve to create opportunities for open dialogue (see also Cunliffe and Eriksen, 2011). A practical way of achieving open dialogue would be, for example, the introduction of group exercises (Philipps, 2014) in which applicants for different jobs at the same organization engage in problem-solving activities together. Exercises like this can bring to the fore to what extent applicants are able to engage 
in the facilitation of voice expression in a dialogic way (for similar ideas in the context of group payments, incentivation, and promotion, see also Pless, 1999, p. 170). At the same time, reorientation towards polyphonic recruitment can also help restore one of the core ideas of diversity management; that is, realizing the potentials for creativity and innovation that lies in bringing together diverse and heterogeneous viewpoints (e.g., Bassett-Jones, 2005).

However, one might object that even in a polyphonic environment new members may eventually become assimilated into a homogeneous organizational culture and may lose their potential to contribute to its polyphony. Popular measures of diversity management, such as mentoring programs, can even intensify such processes of homogenization (Gilbert et al., 1999). In this context, our viewpoint stresses that organizational cultures are communicatively constituted, as well (see Cooren et al., 2013). Consequently, to avoid tendencies towards a culture of homogeneity, it is important to establish mechanisms that make the acceptance of otherness more likely (Shotter, 2008). The creation of open communication between superiors and subordinates whose goal is power-sharing through participatory processes of decision making (Sadri and Tran, 2002) can be seen as a first and important step toward facilitating an open communicative culture. We will return to this point when we look at the facilitation of the interplay of organizational and contextual voices through day-to-day practices.

\section{(2) Creating Structural Resonance for Contextual Voices}

As argued above, our constitutive-polyphonic viewpoint emphasizes that organizations are co-constituted not only by the expression of voices of organizational members, but also by the voices of non-members. This contextual co-constitution of organizational phenomena is especially pronounced in today's age of the 'networked society' (Schultz et al., 2013) or 'stakeholder society' (Maak and Pless, 2006). While existing research on diversity management tends to focus on the differences and boundaries between organizational 
members (e.g., Kalonaityte, 2009), the constitutive-polyphonic perspective enables us to illustrate how the boundaries of the organization are established vis-à-vis its environment in and through communication.

In line with these considerations, our constitutive-polyphonic approach highlights the need to establish 'structural resonance' for contextual voices; that is, organizational structures that enable a multitude of contextual voices to become heard in organizational settings. To illustrate the idea of structural resonance let us consider the example of 'issue monitoring', that is, the strategic and proactive observation of media coverage of issues of potential concern for the organization (e.g., Heath and Palenchar, 2009). The Swiss consumer goods firm Nestlé, for instance, recently established a 'Digital Acceleration Team' that monitors on a real-time basis, via traditional or social media, emerging topics, opinions, and conversations that might be important for the corporation, also in order to pre-empt reputational crises (Abramovich, 2013). Such measures increase the likelihood of an organization 'hearing' a range of contextual voices and allow the latter to play a formative role for that organization (see also Christensen and Cornelissen, 2011).

We should point out, however, that even if certain practices of issue management enable organizations to register the plurality of voices in their environment, this does not necessarily translate into allowing these voices to influence the organization's core activities, which are usually guided by criteria of profitability and efficiency and by the 'voices' of marketing, accounting, or finance (see also Schoeneborn and Trittin, 2013). This becomes particularly problematic if this type of monitoring is carried out by an organization's (largely detached) corporate communications or PR division-perhaps even outsourced to an external provider-or if it is used as a mere defense mechanism to buffer critical voices. It follows that structural resonance is not limited to acknowledging symbolically diverse voices, but also 
involves engaging actively with contextual polyphony through processes of change and innovation (see also Christensen et al., 2013).

One way of allowing voices to enter organizational discourses is through new information and communication technologies (ICTs). While we acknowledge that, generally, communication technologies can also lead to behavior that limits polyphony, such as cyber-bullying (e.g., Lutgen-Sandvik and Tracy, 2012), ICTs offer the potential to create new arenas and opportunities for discursive diversity, thus allowing diverse organizational and contextual voices to be heard (see also Gossett, 2006; Kornberger et al., 2006). Social media in particular are known for their capacity to create arenas in which individuals can actively participate in diffuse networks (Whelan et al., 2013) that, in turn, enable organizing for inclusive work environments beyond formal inclusion efforts of diversity management initiatives (Zanoni et al., 2010).

For example, in 2011, the Swiss outdoor clothing corporation Mammut was confronted with protests and public outrage on their social media outlets after an activist criticized the corporation, which is known for its commitment to sustainability, for joining a list of firms that endorsed a pending Swiss law aimed to lessen restrictions on corporate $\mathrm{CO}_{2}$ emissions. Reacting to the outrage within 24 hours, the corporation stated that it would immediately leave that group of companies and apologized for the confusion that its presence on that list had raised about its motives (Tresch, 2011). This example demonstrates that communication platforms such as social media are an important means for opening organizations to contextual voices. At the same time, the Mammut example also shows that simply creating a communication platform is insufficient. Engaging with contextual voices on the one hand and responding to these voices by making internal behavioral changes and adapting business practices on the other demonstrates that an organization is receptive to contextual polyphony and thus resonant. In this case, by withdrawing from the list and continuously improving their 
sustainability activities, Mammut demonstrated responsiveness to the polyphony that included critical voices. Yet, in line with the study by Baumann-Pauly et al. (2013), we assume that it is comparably easier for small and medium-sized enterprises (SMEs), such as Mammut, to establish structural resonance in the sense of establishing a tight link between external communication and internal implementation. In comparison, multinational corporations (MNCs), such as Nestlé, have to deal with a much higher degree of complexity in their value chains and decision-making structures (Baumann-Pauly et al., 2013).

The Mammut example furthermore highlights the necessity to discuss diversity management also in the larger context of corporate social responsibility (CSR). Indeed, CSR scholars suggest that diversity management should be treated as an integral element of CSR strategies (e.g., Bear et al., 2010; Matten and Moon, 2004; for a critical discussion, see Jonsen et al., 2013). Through CSR activities, corporate actors engage in the negotiation of what constitutes appropriate organizational behavior with the society at large (Castelló et al., 2013). If diversity is understood as communicative plurality, a polyphony-resonant organization would allow diverse discourses on CSR issues to be heard and arguments of profitability to be challenged by notions of ethics, responsibility, and equality.

\section{(3) Managing the Interplay of Organizational and Contextual Voices}

The strategic facilitation of organizational polyphony (e.g., through HRM practices) and the creation of opportunities for contextual voices to become heard (e.g., through what we termed 'structural resonance') are important prerequisites for polyphonic organizing; yet, they ultimately remain insufficient if organizations do not facilitate the dynamic interplay between organizational and contextual voices in their day-to-day business activities. Considering that polyphony must be actively encouraged we discuss in the following three important preconditions for practicing polyphonic dialogues (based on the principles of mutual 
recognition, reciprocal trust, mutual enabling, mutual understanding and multi-logical negotiations; Pless, 1998): (a) The role of (responsible) leadership in facilitating polyphonic dialogues, (b) a corresponding inclusive organizational culture in which dissonant voices are accepted and respected and can be uttered, and (c) the implementation of educational measurements to develop the individual competencies of organizational members and nonmembers to engage in organizational polyphony

First, we find it useful to draw on the notion of responsible leadership (e.g., Maak and Pless, 2006; Pless et al., 2012; Voegtlin et al., 2011). This body of literature, which draws primarily on Habermasian discourse ethics (Habermas, 1991), highlights stakeholder dialogues, conflict mediation, collaborative problem solving and decision-making processes, or workshops on creativity and innovation as essential practices for responsible leadership, i.e., leadership that cultivates relationships between the organization and its societal context on the basis of humane and moral values (e.g.,Voegtlin et al., 2011). For instance, Anita Roddick, the founder of the corporation The Body Shop, can serve as an example of this type of leadership (see also Pless, 2007). Roddick was known to value honesty, fairness, respect, and care for others. Based on these values, she applied a business model of corporate responsibility when founding The Body Shop, a corporation that continuous to foster the inclusion of a multitude, and oftentimes dissonant internal and external stakeholder demands based on reciprocal trust (Pless, 2007).

Responsible leadership approaches offer guidance on how organizations can reach consensual agreements with their various stakeholders (i.e. based on mutual recognition and understanding) through dialogue. We argue that these approaches are valuable in the context of diversity management, as well (see also Pless and Maak, 2004). However, our constitutivepolyphonic viewpoint differs from existing works on Habermasian variants of responsible leadership research (e.g., Voegtlin, 2015; Voegtlin et al., 2011) in one important regard: 
While Habermasian discourse ethics implies striving for consensual agreements among the participants in a dialogue, our Bakthinian approach to discourse ethics underscores the importance of dialogues as a process of voice articulation, regardless of whether a consensual agreement between multiple voices can be reached (Gardiner, 2004). This is made possible exactly because, in dialogue, also one and the same individual can bring in various voices (Bakhtin, 1984). Accordingly, within a polyphonic dialogue, responsible leaders would facilitate that participating subjects bring in various, potentially dissonant voices into the conversation, including the contextual voices of absent stakeholders or wider societal discourses (see also Jabri et al., 2008). Managing diversity as polyphony thus implies that responsible leaders in practice mediate and translate between multiple logics of various organizational and contextual voices, in order to deconstruct and therefore manage differences, without negating them (see also Kornberger et al., 2006; Pless, 1998). For example, in the context of CSR, this would mean for responsible leaders to engage account for the contextual voices that critically address the social and environmental impact of the firm's business conduct (Pless, 1998) and to mediate between these voices and organizational voices that follow an economic logic, for instance by translating CSR issues into a 'business case’ rationale (see also Schultz and Wehmeier, 2010).

Moreover, responsible leadership literature emphasizes the ability of leaders, i.e. influential organizational members, to enable the interplay between various voices. Yet, drawing on Bakhtin, who saw the fictional characters of Dostoyevsky' novel be capable to challenge of the author's authority (Bakhtin, 1984; see also Jabri et al., 2008), a constitutive-polyphonic viewpoint implies to assign responsibility to organizational members on various levels (i.e. not only leaders or managers) to act as important facilitators and enablers of both organizational and contextual polyphony (Cunliffe and Eriksen, 2011; Fairhurst, 2008). An insightful example of how 'ordinary’ organizational members become part of organizational 
polyphony in a more 'bottom up’ fashion is the social enterprise Gram Vikas (see also Pless and Appel, 2012). Gram Vikas aims to provide sustainable rural development in India; for this purpose, the organization establishes democratic and self-governing platforms in which the people of the Indian communities can engage in discussions and decisions affecting their lives. Gram Vikas’s procedures of participatory decision-making, shared responsibility, and the establishment of equal opportunity rules foster the ability of all people to raise their voices and to engage with each other in an inclusive way.

Second, a constitutive-polyphonic viewpoint calls for a corresponding organizational culture that may foster the inclusion of a plurality of voices into organizing according to the idea of all voices being “different but equal” (Pless, 1998, p. 321). In the same line of thinking, Pless and Maak (2004) suggest that organizations require diversity management to build upon “principles of recognition, mutual understanding, standpoint plurality and mutual enabling, trust and integrity, that allows for the integration of different and multiple voices into the organizational discourse” (p. 143) - a standpoint that comes close to our argumentation on how to foster proactively the expression of (organizational and contextual) polyphony. In this context, our approach is grounded in the assumption that polyphony arises when independent voices are dynamically combined without merging; in other words, in polyphonic dialogue, each voice is acknowledged for its own logic and tone in response to others (Shotter, 2008). Accordingly, this view implies to embrace dissent and contestation because of their potential to foster innovation as well as organizational and social change (e.g., Carter and Clegg, 2003; Jabri et al., 2008; Kornberger et al., 2006; Pless, 1998). For example, a culture that respects and appreciates polyphony can be cultivated through the implementation of spaces that explicitly allow dissenting and dissonant voices (Whelan, 2013) to engage together in openended dialogues (see also Cunliffe and Eriksen, 2011). 
One example for the appreciation of dissonant voices from organizational practice is the international strategy consulting firm McKinsey, which nurtures as one of its core values the 'obligation to dissent' (Hill, 2011). In other words, even junior employees are encouraged to raise critical concerns, independently of hierarchical rank. To what extent this ideal is actually accomplished in day-to-day activities at McKinsey is an empirical question. However, this example at least shows a cultural appreciation for diversity that is focused on the expression of different voices in an industry that is not necessarily perceived as favoring diversity in terms of classic criteria of diversity management such as gender or ethnicity. Consequently, diversity management practices that rely on a constitutive-polyphonic viewpoint require organizations to implement explicitly communicative mechanisms that emphasize an inclusive environment in which their members feel comfortable and accepted when speaking up (see also Kornberger et al., 2006).

Third, we consider the implementation of educational measurements to be an important prerequisite for facilitating the discursive diversity in organizational settings. However, in contrast to existing approaches of diversity trainings the focus would lie not only on a diverse group composition (e.g., Roberson et al., 2001) but especially also on facilitating the interplay between organizational and contextual voices. In the same context, the contribution of any organizational member to organizational polyphony depends on their abilities to recognize and value different voices, i.e. to engage in an appreciative way with multiple logics (Pless, 1998). Yet, embracing, acknowledging, and respecting worldviews, opinions, or experiences that differ from one's own can be a difficult task. Trainings and educations can foster the cognitive, behavioral, and emotional capacities of organizational members to deal with this polyphony (see also Pless, 1999). Thus, for example, we consider international servicelearning assignments, i.e. programs that involve sending business leaders to foreign countries to work in cross-sectional-partnerships, to be helpful in order to sensitize managers for 
different realities of human existence and to enable them to develop competencies to deal with unresolvable conflicts between multiple parties (and voices) (Pless et al., 2011). We understand such assignments to be fruitful opportunities for gaining experience in facilitating the polyphony of voices that managers potentially encounter in different organizational settings. From a constitutive-polyphonic viewpoint, such competencies of understanding issues from a different perspective should ideally be given to organizational members on various levels and in various job functions.

In addition to prior considerations on how to teach organizational members to accept, understand and engage in a dialogic way with different voices (e.g., Pless et al., 2011; Pless, 1998), a constitutive-polyphonic perspective also implies to expand the focus of educational measurements on polyphony facilitation to organizational non-members. This is because in line with the CCO perspective, we understand organizational membership not necessarily to be a pre-requisite for the co-constitution of the organization (e.g., Dobusch and Schoeneborn 2015). For instance, in the context of CSR, this would imply that corporations would teach representatives of non-governmental organizations (NGOs) on how they can voice their concerns in a way that the likelihood is raised that their arguments can find attentive ears in a corporate setting (e.g., by linking arguments for social and environmental concerns closely with the corporation's business practices and business opportunities of socially responsible behavior).

\section{Conclusion}

\section{Theoretical Contributions}

Our paper contributes to the literature on organizational diversity and diversity management in three main regards. First, we complement the instrumental and critical traditions of research on diversity management with a communication-centered perspective. We drew 
especially on works following the CCO perspective (e.g., Ashcraft et al., 2009; Cooren et al., 2011) and other works from organization studies that understand organizations as polyphonic accomplishments (e.g., Belova et al., 2008; Hazen, 1993; Shotter, 2008) to suggest that existing works on diversity management and practice can be enriched by directing attention to the expression of voices as one important and distinct site of diversification (see also Pless, 1998; 1999). Accordingly, we depart from prior conceptualizations of diversity (e.g., Bell et al., 2011; Cox and Blake, 1991; Robinson and Dechant, 1997; Scott et al., 2011) that are based on sociodemographic individual differences (some of which can hardly be altered). Instead, we reconceptualize diversity as plurality of voices (i.e. individual voices and societal discourses) and arrive at a dynamic understanding of diversity management as a process of polyphonic voice articulation and mediation.

Importantly, we believe that our constitutive-polyphonic reconceptualization of diversity management can also help resolve existing contradictions between the instrumental ('business case') and critical ('social representation') views of diversity management. In particular, by building upon constructive-critical works (e.g., Prasad et al., 2011; Syed and Özbilgin, 2009; Tatli and Özbilgin, 2012), our paper marries instrumental and normative concerns of managing diversity. On the one hand, by switching the goal of diversity management to the maximization of voices and viewpoints in organizational settings, our approach can help bring diversity management practices closer to the actual aim of the business-case argument, i.e. the creativity and innovation that is fostered through a diversity of opinions and viewpoints (e.g., Bassett-Jones, 2005; Scott et al., 2011). On the other hand, our constitutive-polyphonic approach can help organizations to reach what has been called 'discursive representation' (e.g., Geden, 2005), i.e. a status in which different societal voices, discourses, opinions, and viewpoints become visible and present in organizations. In this regard, our theoretical 
proposal adds one important dimension to the ethical considerations of social representation and justice that critical scholars highlight (e.g., Van Dijk et al., 2012).

Second, we add to prior research on diversity management by highlighting the organizational need to establish structural resonance for organizational voices and contextual voices. Prior diversity management research tends to treat organizations as stable entities (or 'containers') in which communication processes occur. In contrast, our constitutive-polyphonic perspective considers both organizational and contextual voices to play a formative role in the communicative constitution of organizations (see also Kuhn, 2008) and thus importantly contribute to the discursive diversity of organizations. However, as we have argued, the latter depends on the organization's capacities for structural resonance; that is, on the extent to which contextual voices become 'heard' in organizational settings. In this regard, our paper underscores the fundamental embeddedness of organizations in larger networks of societal relations (see also Pless, 1998, 1999; Schultz et al., 2013) and thus stands in one line with prior works that have propagated a stronger recognition of contextual voices and discourses in diversity management (e.g., Kirby and Harter, 2003; Prasad et al., 2011).

One further important implication of acknowledging the importance of contextual polyphony for organizations is that diversity management can be seen as an integral part of CSR and the management of stakeholder relations (see e.g., Matten and Moon, 2004; Maak and Pless, 2006). However, the inclusion of external voices creates new challenges for organizations to maintain the status of a unified and identifiable social entity. Future research will need to investigate how diversity management can be further developed into a form of boundary management that finds a fruitful balance between maintaining organizational identity and the inclusion of diverse voices (see also Dobusch and Schoeneborn, 2015). 
Third, our paper helps to further advance CCO thinking as a theoretical endeavor (Ashcraft et al., 2009; Cooren et al., 2011). While research in this theory stream tends to be primarily descriptive in character, we extend the CCO perspective by unfolding some of the ethicalnormative implications of a communication-centered view of organization (see also the recent calls by Scherer and Rasche, forthcoming; Schoeneborn and Sandhu, 2013). To do so, we have suggested to extend the CCO perspective by drawing on the work of Bakhtin (1984) and his followers (e.g., Belova et al., 2008; Hazen, 1993; Shotter, 2008) on the importance of polyphony for organizations. However, in contrast to Habermasian approaches (e.g., Scherer and Palazzo, 2007; Scherer and Rasche, forthcoming), our Bakhtin-inspired proposal underscores that organizations should embrace dissonant, even dissenting, voices (see also Whelan et al., 2013).

In the same context, our constitutive-polyphonic approach also reveals important crossconnections with prior works that are concerned with the usefulness of polyphonic dialogues in organizational settings. In this regard, our study particularly follows the footsteps of Pless (1998, 1999). Our paper does not only make her works (that were partly published in German language) visible to an international audience but also contribute to her work by embedding it into a larger communicative ontology of organizations that has been developed over the past decades (Nicotera, 2013). By disentangling the concept of voice from particular individuals, we help move the analytical focus to communicative events as sites of voice expression as the main unit of analysis and link this issue to the fundamental question of the communicative (co-)constitution of organizations.

\section{Limitations and Outlook on Future Research}

In this final section, we would like to point out some of the limitations of our conceptual inquiry. First, we did not examine the possibility that polyphony may not always lead to 
positive outcomes either for organizations or for individual members (see also Belova, 2010). For example, multiple dissonant voices could conceivably lead to ineffective organizing because of their inability to create a shared understanding (e.g., Kornberger et al., 2006). Moreover, polyphony may overburden some organizational members with demands for personal flexibility and adaptation to a dynamic workplace (e.g., Belova, 2010). With that in mind, we encourage future research to investigate the specific boundary conditions under which the demands of organizational polyphony benefit both organizations and their members. Thus, future research should also consider investigating how various forms of organizations (e.g., business firms or non-profit organizations) differ in their polyphonic nature and subsequent requirements for polyphony maximization.

Furthermore, reducing the constitution of the organization to nothing but communication might sound naïve in some ways (for a similar argument, see Reed, 2010). Of course, organizations manifest themselves not only in symbolic ways (e.g., speech acts), but also in the materiality (e.g., technologies, objects, sites, and bodies) through which we experience reality (e.g., Ashcraft et al., 2009). However, our main claim is that communication is the primary mechanism through which material elements are shaped and transform organizing (Cooren, 2010). In that respect, our proposal is also aligned with other works that underline the close relationship between the discursive and material processes that form organizations in light of the increasing demands for workforce diversification (e.g., Ashcraft, 2013b; Ashcraft and Mumby, 2004).

In order to further advance the constitutive-polyphonic perspective on diversity management, we encourage scholars to take into account also the role non-human agency —an idea that has a particularly strong tradition within CCO theorizing (see Ashcraft et al. 2009) and that allows to further go beyond the works of Pless $(1998,1999)$. Cooren has added the notion of ‘ventriloquism' to the CCO debate (Cooren and Sandler, 2014; Cooren, 2010, 2012), i.e., the 
idea that all kinds of persons, but also non-human entities or 'figures' (Cooren and Sandler, 2014), such as the concept of diversity management, can gain agency in their own right in organizational settings. This idea goes beyond our current approach as well as those of our precursors (e.g., Pless, 1998, 1999). In the same line of thinking, one can argue that the ways in which differences are manifested in organizational settings are also due to the agentic capacities of the diversity concept as it has been institutionalized, e.g., in the form of dominant gender norms (see also McDonald, 2013). It follows that diversity as a concept would need to be diversified as such - that is, to allow for various meanings-in order to facilitate polyphony. Following these considerations, we believe that a diversification of the diversity concept will be an important task for future research. 


\section{REFERENCES}

Abramovich, G. (2013). Nestle’s Blackshaw: Digital transformation requires training, testing. CMO. http://www.cmo.com/articles/2013/11/6/nestles_blackshaw_digital.html

Adler, P. S., Forbes, L. C., \& Willmott, H. (2007). Critical management studies. Academy of Mangement Annals, 1(1), 119-179.

Alcázar, F. M., Fernández, P. M. R., \& Gardey, G. S. (2013). Workforce diversity in strategic human resource management models: A critical review of the literature and implications for future research. Cross Cultural Management: An International Journal, 20(1), 39-49.

Ashcraft, K. L. (2013). The glass slipper: “Incorporating” occupational identity in management studies. Academy of Management Review, 38(1), 6-31.

Ashcraft, K. L., Kuhn, T. R., \& Cooren, F. (2009). Constitutional amendments: “Materializing” organizational communication. The Academy of Management Annals, 3(1), 1-64.

Ashcraft, K. L., \& Mumby, D. K. (2004). Organizing a critical communicology of gender and work. International journal of the Sociology of Language, 166, $19-43$.

Ashkanasy, N. M., Härtel, C. E. J., \& Daus, C. S. (2002). Diversity and emotion: The new frontiers in organizational behavior research. Journal of Management, 28(3), 307-338.

Austin, J. L. (1962). How to do things with words. Oxford, UK: Oxford University Press.

Axley, S. R. (1984). Managerial and organizational communication in terms of the conduit metaphor. Academy of Management Review, 9(3), 428-437.

Ayoko, O. (2007). Communication openness, conflict events and reactions to conflict in culturally diverse workgroups. Cross Cultural Management: An International Journal, 14(2), 105-124.

Bakhtin, M. (1984). Problems of Dostoevsky’s poetics. (Emer, Ed.). Minneapolis: University of Minnesota Press. 
Bassett-Jones, N. (2005). The paradox of diversity management, creativity and innovation. Creativity and innovation management, 14(2), 169-175.

Baumann-Pauly, D., Wickert, C., Spence, L. J., \& Scherer, A. G. (2013). Organizing corporate social responsibility in small and large firms: Size matters. Journal of Business Ethics, 115(4), 693-705.

Bear, S., Rahman, N., \& Post, C. (2010). The impact of board diversity and gender composition on corporate social responsibility and firm reputation. Journal of Business Ethics, 97(2), 207-221.

Bell, M. P., Özbilgin, M. F., Beauregard, T. A., \& Sürgevil, O. (2011). Voice, silence, and diversity in 21st century organizations: Strategies for inclusion of gay, lesbian, bisexual, and transgender employees. Human Resource Management, 50(1), 131-146.

Belova, O. (2010). Polyphony and the sense of self in flexible organizations. Scandinavian Journal of Management, 26(1), 67-76.

Belova, O., King, I., \& Sliwa, M. (2008). Introduction: Polyphony and organization studies: Mikhail Bakhtin and beyond. Organization Studies, 29(4), 493-500.

Bencherki, N., \& Cooren, F. (2011). Having to be: The possessive constitution of organization. Human Relations, 64(12), 1579-1607.

Bissett, N. (2004). Diversity writ large: Forging the link between diverse people and diverse organisational possibilities. Journal of Organizational Change Management, 17(3), 315-325.

Blaschke, S., Schoeneborn, D., \& Seidl, D. (2012). Organizations as networks of communication episodes: Turning the network perspective inside out. Organization Studies, 33(7), 879-906.

Brown, A. (2006). A narrative approach to collective identities. Journal of Management Studies, 43(4), 731-753.

Brummans, B., Cooren, F., Robichaud, D., \& Taylor, J. R. (2014). Approaches in research on the communicative constitution of organizations. In L. L. Putnam \& D. Mumby (Eds.), Sage handbook of organizational communication (3rd ed., pp. 173-194). London, UK: Sage Publications. 
Carter, C., \& Clegg, S. (2003). The polyphonic spree: The case of the Liverpool dockers. Industrial Relations Journal, 34(4), 290-304.

Castelló, I., Morsing, M., \& Schultz, F. (2013). Communicative dynamics and the polyphony of corporate social responsibility in the network society. Journal of Business Ethics, 118(4), 683-694.

Christensen, L. T., \& Cornelissen, J. (2011). Bridging corporate and organizational communication: Review, development and a look to the future. Management Communication Quarterly, 25(3), 383-414.

Christensen, L. T., Firat, A. F., \& Torp, S. (2008). The organisation of integrated communications: Toward flexible integration. European Journal of Marketing, 42(3/4), 423-452.

Christensen, L. T., Morsing, M., \& Thyssen, O. (2013). CSR as aspirational talk. Organization, 20(3), 372-393.

Christensen, L. T., Morsing, M., \& Thyssen, O. (2015). The polyphony of values and the value of polyphony. Journal for Communication Studies, 8(1), 9-25.

Cooren, F. (2004). Textual agency: How texts do things in organizational settings. Organization, 11(3), 373393.

Cooren, F. (2010). Action and agency in dialogue: Passion, incarnation and ventriloquism. Amsterdam: John Benjamins Publishing.

Cooren, F. (2012). Communication theory at the center: Ventriloquism and the communicative constitution of reality. Journal of Communication, 62(1), 1-20.

Cooren, F., Brummans, B. H. J. M., Benoit-Barné, C., \& Matte, F. (2013). The communicative constitution of organizational culture: A question of cultivation. In Faces da cultura e da comunicação organizacional (Faces of organizational culture and communication) (Vol. 3, pp. 129-152). Sao Caetano do Sul, Brazil: Difusao Editora.

Cooren, F., Kuhn, T., Cornelissen, J., \& Clark, T. (2011). Communication, organizing and organization: An overview and introduction to the special issue. Organization Studies, 32(9), 1149-1170. 
Cooren, F., \& Sandler, S. (2014). Polyphony, ventriloquism, and constitution: In dialogue with Bakhtin. Communication Theory, 24(3), 225-244.

Cox Edmondson, V., Gupte, G., Draman, R. H., \& Oliver, N. (2009). Focusing on communication strategy to enhance diversity climates. Journal of Communication Management, 13(1), 6-20.

Cox, T. (1991). The multicultural organization. Academy of Management Executive, 5(2).

Cox, T. H., \& Blake, S. (1991). Managing cultural diversity: Implications for organizational competitiveness. Academy of Management Executive, 5(3), 45-56.

Craig, R. T. (1999). Communication theory as a field. Communication Theory, 9(2), 119-161.

Cunliffe, A. L., \& Eriksen, M. (2011). Relational leadership. Human Relations, 64(11), 1425-1449.

Dobusch, L., \& Schoeneborn, D. (2015). Fluidity, Identity, and Organizationality: The Communicative Constitution of Anonymous. Journal of Management Studies.

Dutchnews.nl. (2014). KPN revises “women first” policy to focus on ethnic minorities. DutchNews.nl. http://www.dutchnews.nl/news/archives/2014/09/kpn_revises_women_first_policy.php. Accessed 23 March 2015

Eastman, W., \& Santoro, M. (2003). The importance of value diversity in corporate life. Business Ethics Quarterly, 13(4), 433-452.

Fairhurst, G. T. (2008). Discursive leadership: A communication alternative to leadership psychology. Management Communication Quarterly, 21(4), 510-521.

Findler, L., Wind, L. H., \& Mor Barak, M. E. (2007). The challenge of workforce management in a global society: Modeling the relationship between diversity, inclusion, organizational culture, and employee wellbeing, job satisfaction. Administration in Social Work, 31(3), 63-94.

Flores, L. A., \& McPhail, M. L. (1997). A dialogic exposition into the social (re) construction of race, gender, and crime. Critical Studies in Mass Communication, 14(1), 106-122. 
Francoeur, C., Labelle, R., \& Sinclair-Desgagné, B. (2007). Gender diversity in corporate governance and top management. Journal of Business Ethics, 81(1), 83-95.

Freeman, C. (2014). Diversity programs increasingly focus on work styles and values, study reveals. Bloomberg BNA. http://www.bna.com/diversity-programs-increasingly-n17179881842/

Gardiner, M. E. (2004). Wild publics and grotesque symposiums: Habermas and Bakhtin on dialogue, everyday life and the public sphere. The Sociological Review, 52, 28-48.

Geden, O. (2005). The discursive representation of masculinity in the Freedom Party of Austria (FPÖ). Journal of Language and Politics, 4(3), 397-420.

Geiger, D., \& Antonacopoulou, E. (2009). Narratives and organizational dynamics: Exploring blind spots and organizational inertia. The Journal of Applied Behavioral Science, 45(3), 411-436.

Gilbert, J. A., \& Ivancevich, J. M. (2000). Valuing diversity: A tale of two organizations. Academy of Management Perspectives, 14(1), 93-105.

Gilbert, J. A., Stead, B. A., \& Ivancevich, J. M. (1999). Diversity management: A new organizational paradigm. Journal of Business Ethics, 21(1), 61-76.

Gossett, L. M. (2006). My Job sucks: Examining counterinstitutional web sites as locations for organizational member voice, dissent, and resistance. Management Communication Quarterly, 20(1), 63-90.

Gotsis, G., \& Koretzi, Z. (2013). Ethical paradigms as potential foundations of diversity management initiatives in business organizations. Journal of Organizational Change Management, 26(6), 948-976.

Grimes, D. S., \& Richard, O. C. (2003). Could communication form impact organization’s experience with diversity? Journal of Business Communication, 40(1), 7-27.

Groggins, A., \& Ryan, A. M. (2013). Embracing uniqueness: The underpinnings of a positive climate for diversity. Journal of Occupational and Organizational Psychology, 86(2), 264-282. 
Guillaume, Y. R. F., Dawson, J. F., Woods, S. A., Sacramento, C. A., \& West, M. A. (2013). Getting diversity at work to work: What we know and what we still don’t know. Journal of Occupational and Organizational Psychology, 86(2), 123-141.

Habermas, J. (1991). Moral consciousness and communicative action. Cambridge: MIT Press.

Harrison, D. A., \& Klein, K. J. (2007). What's the difference? Diversity constructs as separation, variety, or disparity in organizations. Academy of Management Review, 32(4), 1199-1228.

Hazen, M. (1993). Towards polyphonic organization. Journal of Organizational Change Management, 6(5), 1526.

Heath, R. L., \& Palenchar, M. J. (2009). Strategic issues management: Organizations and public policy challenges. Sage Publications, Inc.

Helgesen, S. (2014). Values-based diversity - The challenges and strengths of many. The Economist Intelligence Unit. http://www.successfactors.com/en_us/download.html?a=/content/dam/successfactors/en_us/resources/broc hures/diversity-report.pdf. Accessed 1 December 2014

Hill, A. (2011). Inside McKinsey. Financial Times Magazine. http://www.ft.com/cms/s/2/0d506e0e-1583-11e1b9b8-00144feabdc0.html

Ivancevich, J. M., \& Gilbert, J. A. (2000). Diversity management: Time for a new approach. Public Personnel Management, 29(1), 75-92.

Jabri, M., Adrian, A. D., \& Boje, D. (2008). Reconsidering the role of conversations in change communication: A contribution based on Bakhtin. Journal of Organizational Change Management, 21(6), 667-685.

James, E. H. (2000). Race-related differences in promotions and support: Underlying effects of human and social capital. Organization Science, 11(5), 493-508.

Janssens, M., \& Zanoni, P. (2005). Many diversities for many services: Theorizing diversity (management) in service companies. Human Relations, 58(3), 311-340. 
Janssens, M., \& Zanoni, P. (2014). Alternative diversity management: Organizational practices fostering ethnic equality at work. Scandinavian Journal of Management, 30(3), 317-331.

Jonsen, K., Tatli, A., Özbilgin, M. F., \& Bell, M. P. (2013). The tragedy of the uncommons: Reframing workforce diversity. Human Relations, 66(2), 271-294.

Kalonaityte, V. (2009). The case of vanishing borders: Theorizing diversity management as internal border control. Organization, 17(1), 31-52.

Kamenou, N., \& Fearfull, A. (2006). Ethnic minority women: A lost voice in HRM. Human Resource Management Journal, 16(2), 154-172.

Kearney, E., Gebert, D., \& Voelpel, S. C. (2009). When and how diversity benefits teams: The importance of team members’ need for cognition. Academy of Management Journal, 52(3), 581-598.

Kirby, E. L., \& Harter, L. M. (2003). Speaking the language of the bottom-line: The metaphor of "managing diversity.” Journal of Business Communication, 40(1), 28-49.

Kirton, G., \& Greene, A.-M. (2009). The costs and opportunities of doing diversity work in mainstream organisations. Human Resource Management Journal, 19(2), 159-175.

Kornberger, M., Clegg, S. R., \& Carter, C. (2006). Rethinking the polyphonic organization: Managing as discursive practice. Scandinavian Journal of Management, 22(1), 3-30.

Kuhn, T. (2008). A communicative theory of the firm: Developing an alternative perspective on intraorganizational power and stakeholder relationships. Organization Studies, 29(8-9), 1227-1254.

Kuhn, T. (2012). Negotiating the micro-macro divide: Thought leadership from organizational communication for theorizing organization. Management Communication Quarterly, 26(4), 543-584.

Kulik, C. T. (2014). Working below and above the line: The research-practice gap in diversity management. Human Resource Management Journal, 24(2), 129-144.

Labucay, I. (2015). Diversity management and performance: paving the way for a revised business case. European J. of International Management, 9(4), 425. 
Letiche, H. (2010). Polyphony and its other. Organization Studies, 31(3), 261-277.

Litvin, D. R. (1997). The discourse of diversity: From biology to management. Organization, 4(2), 187-209.

Maak, T., \& Pless, N. M. (2006). Responsible leadership in a stakeholder society: A relational perspective. Journal of Business Ethics, 66(1), 99-115.

Matten, D., \& Moon, J. (2004). Corporate social responsibility education in Europe. Journal of Business Ethics, 54(4), 323-337.

McDonald, J. (2013). Conforming to and resisting dominant gender norms: How male and female nursing students do and undo gender. Gender, Work \& Organization, 20(5), 561-579.

McPhee, R. D., \& Zaug, P. (2000). The communicative constitution of organizations: A framework for explanation. The Electronic Journal for Communication, 10(1-2).

Metcalfe, B. D., \& Woodhams, C. (2012). Introduction: New directions in gender, diversity and organization theorizing: Re- imagining feminist post- colonialism, transnationalism and geographies of power. International Journal of Management Reviews, 14(2), 123-140.

Milliken, F. J., \& Martins, L. L. (1996). Searching for common threads: Understanding the multiple effects of in organizational diversity. Academy of Management Review, 21(2), 402-433.

Naff, K. C., \& Kellough, J. E. (2003). Ensuring employment equity: Are federal diversity programs making a difference? International Journal of Public Administration, 26(12), 1307-1336.

Nelson, J. K., \& Wolf, P. P. (2012). Developing efficacy beliefs for ethics and diversity management. Academy of Management Learning \& Education, 11(1), 49-68.

Nicotera, A. M. (2013). Organizationas as entitative beings: Some ontological implications of communicative constitution. In D. Robichaud \& F. Cooren (Eds.), Organization and Organizing: Materiality, Agency and Discourse (pp. 66-89). New York: Routledge.

Nishii, L. H., \& Özbilgin, M. F. (2007). Global diversity management: Towards a conceptual framework. The International Journal of Human Resource Management, 18(11), 1883-1894. 
Philipps, K. W. (2014). How diversity makes us smarter. Scientific American. http://www.scientificamerican.com/article/how-diversity-makes-us-smarter/

Pietikäinen, S., \& Dufva, H. (2006). Voices in discourses: Dialogism, critical discourse analysis and ethnic identity. Journal of Sociolinguistics, 10(2), 205-224.

Pless, N. (1998). Corporate Caretaking: Neue Wege der Gestaltung organisationaler Mitweltbeziehungen. Marburg: Metropolis.

Pless, N. (1999). Von der Dominanz zur Partnerschaft: Erfolgreiches Diversitätsmanagement erfordert einen Paradigmenwechsel. Die Unternehmung: Swiss Journal of Business Research and Practice, 53(3), 159175.

Pless, N. M. (2007). Understanding resonsible leadership: Role identity and motivational drivers. Journal of Business Ethics, 74(4), 437-456.

Pless, N. M., \& Appel, J. (2012). In pursuit of dignity and social justice: Changing lives through $100 \%$ inclusion: How Gram Vikas fosters sustainable rural development. Journal of Business Ethics, 111(3), 389-411.

Pless, N. M., Maak, T., \& Stahl, G. K. (2011). Developing responsible global leaders through international service-learning programs: The Ulysses experience. Academy of Management Learning and Education, 10(2), 237-260.

Pless, N. M., Maak, T., \& Waldman, D. A. (2012). Different approaches toward doing the right thing: Mapping the responsibility orientations of leaders. Academy of Management Perspectives, 26(4), 51-65.

Pless, N., \& Maak, T. (2004). Building an inclusive diversity culture: Principles, processes and practice. Journal of Business Ethics, 54(2), 129-147.

Prasad, A., Prasad, P., \& Mir, R. (2011). “One mirror in another”: Managing diversity and the discourse of fashion. Human Relations, 64(5), 703-724. 
Reed, M. (2010). Is communication constitutive of organization? Management Communication Quarterly, 24(1), $151-157$.

Rennison, B. W. (2009). Kampen om integrationen: Diskurser om etnisk mangfoldighedsledelse. Copenhagen: Hans Reitzel.

Riach, K. (2009). Managing “difference”: Understanding age diversity in practice. Human Resource Management Journal, 19(3), 319-335.

Roberson, L., Kulik, C. T., \& Pepper, M. B. (2001). Designing effective diversity training: Influence of group composition and trainee experience. Journal of Organizational Behavior, 22(8), 871-885.

Robinson, G., \& Dechant, K. (1997). Building a business case for diversity. The Academy of Management Executive, 11(3), 21-31.

Sadri, G., \& Tran, H. (2002). Managing your diverse workforce through improved communication. Journal of Management Development, 21(3), 227-237.

Scherer, A. G., \& Palazzo, G. (2007). Toward a political conception of corporate responsibility: Business and society seen from a Habermasian perspective. The Academy of Management Review, 32(4), 1096-1120.

Scherer, A. G., \& Rasche, A. (forthcoming). Organizations as communication: The (potential) contribution of Habermasian philosophy. In S. Blaschke \& D. Schoeneborn (Eds.), Organizations as communication: Intercontinental perspectives.

Schoeneborn, D., Blaschke, S., Cooren, F., McPhee, R. D., Seidl, D., \& Taylor, J. R. (2014). The three schools of CCO thinking: Interactive dialogue and systematic comparison. Management Communication Quarterly, 28(2), 285-316.

Schoeneborn, D., \& Sandhu, S. (2013). When birds of different feather flock together: The emerging debate on “Organization as Communication” in the German-Speaking Countries. Management Communication Quarterly, 27(2), 303-313. 
Schoeneborn, D., \& Scherer, A. G. (2012). Clandestine organizations, al Qaeda, and the paradox of (in)visibility: A response to Stohl and Stohl. Organization Studies, 33(7), 963-971.

Schoeneborn, D., \& Trittin, H. (2013). Transcending transmission: Towards a constitutive perspective on CSR communication. Corporate Communications: An International Journal, 18(2), 193-211.

Schultz, F., Castelló, I., \& Morsing, M. (2013). The construction of corporate social responsibility in network societies: A communication view. Journal of Business Ethics, 115(4), 681-692.

Schultz, F., \& Wehmeier, S. (2010). Institutionalization of corporate social responsibility within corporate communications: Combining institutional, sensemaking and communication perspectives. Corporate Communications: An International Journal, 15(1), 9-29.

Schwabenland, C., \& Tomlinson, F. (2015). Shadows and light: Diversity management as phantasmagoria. Human Relations.

Scott, K. A., Heathcote, J. M., \& Gruman, J. A. (2011). The diverse organization: Finding gold at the end of the rainbow. Human Resource Management, 50(6), 735-755.

Searle, J. R. (1969). Speech acts: An essay in the philosophy of language. Cambridge: Cambridge University Press.

Shelton, C. D., McKenna, M. K., \& Darling, J. R. (2002). Leading in the age of paradox: Optimizing behavioral style, job fit and cultural cohesion. Leadership Organization Development Journal, 23(7), 372-379.

Shotter, J. (2008). Dialogism and polyphony in organizing theorizing in organization studies: Action guiding anticipations and the continuous creation of novelty. Organization Studies, 29(4), 501-524.

Siciliano, J. I. (1996). The relationship of board member diversity to organizational performance. Journal of Business Ethics, 15(12), 1313-1320.

Singh, B., Winkel, D. E., \& Selvarajan, T. T. (2013). Managing diversity at work: Does psychological safety hold the key to racial differences in employee performance? Journal of Occupational and Organizational Psychology, 86(2), 242-263. 
Singh, V., \& Point, S. (2006). (Re)Presentations of gender and ethnicity in diversity statements on European company websites. Journal of Business Ethics, 68(4), 363-379.

Styhre, A., \& Eriksson-Zetterquist, U. (2008). Thinking the multiple in gender and diversity studies: Examining the concept of intersectionality. Gender in Management: An International Journal, 23(8), 567-582.

Swan, E. (2009). Commodity diversity: Smiling faces as a strategy of containment. Organization, 17(1), 77-100.

Syed, J., \& Özbilgin, M. (2009). A relational framework for international transfer of diversity management practices. The International Journal of Human Resource Management, 20(12), 2435-2453.

Tatli, A. (2011). A multi- layered exploration of the diversity management field: Diversity discourses, practices and practitioners in the UK. British Journal of Management, 22(2), 238-253.

Tatli, A., \& Özbilgin, M. F. (2012). An emic approach to intersectional study of diversity at work: A Bourdieuan framing. International Journal of Management Reviews, 14(2), 180-200.

Taylor, J. R., \& Cooren, F. (1997). What makes communication “organizational”? How the many voices of a collectivity become the one voice of an organization. Journal of Pragmatics, 27(4), 409-438.

Taylor, J. R., \& Van Every, E. J. (2000). The emergent organization. Communication as its site and surface. Mahwah, NJ: Lawrence Erlbaum Associates, Publishers.

Taylor, J. R., \& Van Every, E. J. (2014). When organization fails: Why authority matters. New York, NY: Routledge.

Tienari, J., \& Nentwich, J. (2012). The “doing” perspective on gender and diversity. In M. A. Danowitz, E. Hanappi-Egger, \& H. Mensi-Klarbach (Eds.), Diversity in organizations. Concepts and practices (pp. 109-134). Basingstoke, UK: Palgrave Macmillan.

Tomlinson, F., \& Schwabenland, C. (2009). Reconciling competing discourses of diversity? The UK non-profit sector between social justice and the business case. Organization, 17(1), 101-121.

Tresch, H. (2011). Wenn der “Shitstorm” losgetreten. Tagesanzeiger. http://www.tagesanzeiger.ch/digital/internet/Wenn-derShitstorm-losgetreten/story/28067592 
Van Dijk, H., Van Engen, M., \& Paauwe, J. (2012). Reframing the business case for diversity: A values and virtues perspective. Journal of Business Ethics, 111, 73-84.

Van Knippenberg, D., \& Schippers, M. C. (2007). Work group diversity. Annual Review of Psychology, 58, 515-41.

Van Laer, K., \& Janssens, M. (2011). Ethnic minority professionals’ experiences with subtle discrimination in the workplace. Human Relations, 64(9), 1203-1227.

Voegtlin, C. (2015). What does it mean to be responsible? Addressing the missing responsibility dimension in ethical leadership research. Leadership.

Voegtlin, C., Patzer, M., \& Scherer, A. G. (2011). Responsible leadership in global business: A new approach to leadership and its multi-level outcomes. Journal of Business Ethics, 105(1), 1-16.

Wehmeier, S., \& Winkler, P. (2013). Expanding the bridge, minimizing the gaps: Public relations, organizational communication, and the idea that communication constitutes organization. Management Communication Quarterly, 27(2), 280-290.

Whelan, G. (2013). Corporate constructed and dissent enabling public spheres: Differentiating dissensual from consensual corporate social responsibility. Journal of Business Ethics, 115(4), 755-769.

Whelan, G., Moon, J., \& Grant, B. (2013). Corporations and citizenship arenas in the age of social media. Journal of Business Ethics, 118(4), 777-790.

Williams, K., \& O’Reilly, C. (1998). Demography and diversity in organizations: A review of 40 years of research. Research in Organizational Behavior, 20, 77-140.

Wright, P., Ferris, S. P., Hiller, J. S., \& Kroll, M. (1995). Competitiveness through management of diversity: Effects on stock price valuation. Academy of Management Journal, 38(1), 272-287.

Zanoni, P. (2011). Diversity in the lean automobile factory: Doing class through gender, disability and age. Organization, 18(1), 105-127. 
Zanoni, P., \& Janssens, M. (2004). Deconstructing difference: The rhetoric of human resource managers’ diversity discourses. Organization Studies, 25(1), 55-74.

Zanoni, P., Janssens, M., Benschop, Y., \& Nkomo, S. (2010). Guest editorial: Unpacking diversity, grasping inequality: Rethinking difference through critical perspectives. Organization, 17(1), 9-29. 


\begin{tabular}{|c|c|c|c|}
\hline & $\begin{array}{l}\text { Instrumental } \\
\text { perspective }\end{array}$ & $\begin{array}{c}\text { Critical } \\
\text { perspective }\end{array}$ & $\begin{array}{c}\text { Constitutive-polyphonic } \\
\text { perspective }\end{array}$ \\
\hline Unit of analysis & $\begin{array}{l}\text { Attributes that account for } \\
\text { differences between } \\
\text { individuals }\end{array}$ & $\begin{array}{l}\text { Social construction of } \\
\text { attributes that account for } \\
\text { differences between } \\
\text { individuals }\end{array}$ & $\begin{array}{l}\text { Communicative events } \\
\text { that can involve } \\
\text { organizational and/or } \\
\text { contextual voices }\end{array}$ \\
\hline $\begin{array}{l}\text { Level of } \\
\text { analysis }\end{array}$ & $\begin{array}{l}\text { Individual/group level } \\
\text { (workforce diversity) }\end{array}$ & $\begin{array}{l}\text { Individual/group level } \\
\text { (workforce diversity) }\end{array}$ & $\begin{array}{l}\text { Communication level } \\
\text { (plurality of voices that } \\
\text { become expressed in } \\
\text { communicative events) }\end{array}$ \\
\hline $\begin{array}{l}\text { Understanding } \\
\text { of diversity }\end{array}$ & $\begin{array}{l}\text { Diversity as a managerial } \\
\text { variable that is based on } \\
\text { (sociodemographic) } \\
\text { differences among } \\
\text { individuals }\end{array}$ & $\begin{array}{l}\text { The meaning of diversity } \\
\text { is subject to social } \\
\text { construction and political } \\
\text { power struggles }\end{array}$ & $\begin{array}{l}\text { Diversity as the plurality } \\
\text { of different organizational } \\
\text { and contextual voices } \\
\text { ('discursive diversity') }\end{array}$ \\
\hline $\begin{array}{l}\text { Role of } \\
\text { communication } \\
\text { in diversity } \\
\text { management }\end{array}$ & $\begin{array}{l}\text { Communication supports } \\
\text { or interferes with } \\
\text { organizational } \\
\text { performance goals }\end{array}$ & $\begin{array}{l}\text { Communication } \\
\text { perpetuates or challenges } \\
\text { inequalities and power } \\
\text { relations }\end{array}$ & $\begin{array}{l}\text { Diversity management is } \\
\text { one of several } \\
\text { communicative practices } \\
\text { that (co-) } \\
\text { constitute the } \\
\text { organization }\end{array}$ \\
\hline $\begin{array}{l}\text { Notion of } \\
\text { organizational } \\
\text { communication }\end{array}$ & $\begin{array}{l}\text { Homophonic: single- } \\
\text { voiced, controlled, } \\
\text { purposeful }\end{array}$ & $\begin{array}{l}\text { Radical-critical views: } \\
\text { communication as a tool } \\
\text { that is exploited by firms } \\
\text { Constructive-critical } \\
\text { views: language in use as } \\
\text { a dynamic political } \\
\text { process in organizational } \\
\text { settings }\end{array}$ & $\begin{array}{l}\text { Polyphonic: multiple, } \\
\text { interrelated, dynamic, } \\
\text { sometimes contradictory } \\
\text { and dissonant voices }\end{array}$ \\
\hline $\begin{array}{l}\text { Rationale } \\
\text { pro/contra } \\
\text { diversity } \\
\text { management }\end{array}$ & $\begin{array}{l}\text { Business case argument: } \\
\text { Diversity management is } \\
\text { useful as a tool to foster } \\
\text { competitive advantage } \\
\text { and (team) performance }\end{array}$ & $\begin{array}{l}\text { Radical-critical views: } \\
\text { Rejection of diversity } \\
\text { management as a source } \\
\text { domination, alienation, } \\
\text { and injustice; } \\
\text { Constructive-critical } \\
\text { views: Diversity } \\
\text { management is desirable } \\
\text { if it fosters the inclusion } \\
\text { and social representation } \\
\text { of individuals in } \\
\text { organizational settings }\end{array}$ & $\begin{array}{l}\text { Reconciliation of } \\
\text { business case with social } \\
\text { representation arguments } \\
\text { by switching the focus to } \\
\text { 'discursive diversity' as a } \\
\text { source of innovation and } \\
\text { change and representation } \\
\text { of societal voices }\end{array}$ \\
\hline
\end{tabular}

Table 1: Comparison of the instrumental, critical, and constitutive-polyphonic perspectives on diversity management and communication 